\title{
Tratamento de Solo Contaminado com Petróleo Utilizando Tensoativos e Peróxido de Hidrogênio
}

\author{
Petroleum Contaminated Soil Treatment \\ Using Surfactant and Hydrogen Peroxide
}

\author{
Carmen Luisa Barbosa Guedes ${ }^{1}$; Caryna Januário Correr²; \\ Ilza Lobo ${ }^{3}$; Otavio Jorge Grigoli Abi-Saab ${ }^{4}$
}

Resumo

O processo de lavagem de solo com substâncias tensoativas, Lauril éter sulfato de sódio (LESS) e Lauril sulfato de sódio (SDS), foi combinado à oxidação química utilizando peróxido de hidrogênio, com vistas à remediação in situ de solo argiloso contaminado com hidrocarbonetos de petróleo. A avaliação da eficiência do processo baseou-se na remoção dos hidrocarbonetos poliaromáticos e na comparação das características físicas e químicas do solo contaminado e não-contaminado oriundos da mesma região. A combinação dessas duas técnicas, lavagem do solo e aplicação de agente oxidante, apresentouse como processo de remediação eficaz para solos argilosos contaminados com derivados de petróleo em regiões subtropicais.

Palavras-chave: Lavagem de Solo. Fluorescência. Agente Oxidante. Óleo Bruto. Hidrocarbonetos Poliaromáticos.

\begin{abstract}
The process of washing soil with surfactants, sodium lauryl ether sulphate (LESS) and sodium lauryl sulphate (SDS) was combined with chemical oxidation using hydrogen peroxide, with a view to in situ remediation of clay soil contaminated with hydrocarbons oil. The evaluation of the efficiency of the procedure was the removal of polyaromatic hydrocarbons and the comparison of physical and chemical characteristics of contaminated soil and uncontaminated from the same region. The combination of these two techniques, soil washing and application of an oxidizing agent, presented as a process of effective remediation for soils contaminated with petroleum products in subtropical regions.
\end{abstract}

Key-words: Soil Washing. Fluorescence. Oxidizing Agent. Crude Oil. Aromatics Hydrocarbons.

1 Professora Doutora do Departamento de Química (CCE) da Universidade Estadual de Londrina. E-mail: carmen@uel.br Graduada em Química e Mestre em Química dos Recursos Naturais pela Universidade Estadual de Londrina.

3 Professora Associada do Departamento de Química (CCE) da Universidade Estadual de Londrina. E-mail: lobo@uel.br

4 Professor Associado do Departamento de Agronomia (CCA) da Universidade Estadual de Londrina. E-mail: abisaab@uel.br 


\section{Introdução}

A poluição ambiental nos dias de hoje, pode ser apontada como um dos grandes problemas dos países desenvolvidos ou em desenvolvimento. Isso é decorrente, não apenas de um, mas de uma série de fatores, como o mau uso dos recursos naturais, a ineficiência da legislação e a falta de consciência ambiental (TEIXEIRA; JARDIM, 2004). A contaminação por poluentes orgânicos perigosos em solo e sedimentos é uma grande preocupação ambiental (CHU; CHAN, 2003). Além do uso generalizado e eliminação inadequada, os derrames acidentais e os vazamentos de hidrocarbonetos de petróleo, solventes orgânicos e compostos poliaromáticos têm resultado em geração de fontes persistentes de contaminação do solo e águas subterrâneas, se tornando um importante problema ambiental, devido aos seus efeitos adversos destes poluentes na saúde humana. A contaminação do subsolo por compostos orgânicos é um processo complexo e difícil de tratar por várias razões, tais como a tendência de adsorção dos contaminantes na matriz solo, a baixa solubilidade destes em água, a taxa limitada de transferência de massa necessária à ocorrência da biodegradação, entre outros.

A crescente industrialização a partir da década de 70, devido ao grande desenvolvimento econômico, causou um aumento no número de postos revendedores de combustíveis ou postos de gasolina. $\mathrm{O}$ vazamento de combustíveis dos tanques de armazenamento pode ocorrer devido a uma série de fatores, como um derramamento durante a operação de transferência de produto para o tanque; vazamentos no sistema devido à corrosão; falhas estruturais do tanque ou da tubulação conectada ao tanque ou então devido à instalação inadequada dos mesmos. O contato de tais substâncias com o meio físico pode afetar diretamente a população, oferecendo riscos à segurança das pessoas, à saúde pública e aos ecossistemas. A contaminação de matrizes ambientais como solo, água e ar tem crescido muito nos últimos anos, assim, novos métodos de remediação ambiental têm sido propostos para o tratamento de locais contaminados. Existem diferentes tecnologias disponíveis para a remediação de locais contaminados com compostos orgânicos. O uso de tensoativos na lavagem do solo é uma tecnologia inovadora, que atualmente está sendo empregada em cerca de $2-3 \%$ de locais contaminados (PARIA, 2008).

Dentre os muitos compostos nocivos ao meio ambiente estão os hidrocarbonetos de petróleo e derivados. Estes compostos incluem alcanos saturados e insaturados de cadeia linear, como o metano, etano, propano, além de compostos orgânicos aromáticos, como os hidrocarbonetos policíclicos aromáticos (HPAs), e ainda hidrocarbonetos aromáticos contendo $\mathrm{N}$ e $\mathrm{S}$ que são prejudiciais ao desenvolvimento de plantas e animais, comprometendo a saúde humana (ZHOU; SUN; LIU, 2005)

A indústria petroleira brasileira, como exemplo, principalmente refinarias e áreas de produção de petróleo, eventualmente se depara com vazamentos de substâncias oleosas (óleo cru e/ou seus derivados) que atinge tanto os recursos hídricos quanto os solos (RIZZO et al., 2006). Devido a este fato, tem ocorrido um aumento das fontes de poluição incluindo, vazamento de combustíveis no transporte e em acidentes no tráfego, descartes terrestres de lubrificantes residuais, estocagem inadequada de óleos lubrificantes, descarga e vazamento de solventes em áreas industriais e particularmente na exploração e prospecção de petróleo (ZHOU; SUN; LIU, 2005).

As tecnologias para tratamento de águas contaminadas com substâncias oleosas se encontram em um estágio de desenvolvimento bem mais avançado do que as tecnologias de solos impactados por essas mesmas substâncias. A remoção de poluentes orgânicos no meio ambiente tem sido um grande desafio tecnológico, pois várias tecnologias de tratamentos convencionais não são capazes de fazê-lo de forma eficiente. Em decorrência desta realidade torna-se cada vez mais urgente a necessidade de se desenvolver uma tecnologia 
eficiente de tratamento dos solos contaminados por hidrocarbonetos de petróleo que comporte grande carga orgânica e que envolva tempo e custo de processos reduzidos (RIZZO et al., 2006).

Métodos de tratamento consistem na descontaminação de solos através da diminuição na concentração e/ou toxidade dos contaminantes, enquanto que, métodos de confinamento resultam na diminuição da mobilidade dos mesmos.

Com o crescimento no interesse de aplicação dos tensoativos na remediação ambiental, diversos autores (BHANDARI; NOVAK; DOVE, 2000; BARATHI, VASUDEVAN, 2001; McCRAY et al., 2001) estudaram a remoção de compostos aromáticos através da técnica de lavagem, utilizando tensoativos como agentes complementares e concluíram que essa abordagem é uma técnica de remediação promissora.

Ouso de tensoativos para remediar contaminantes orgânicos na subsuperfície é, relativamente, uma nova área de aplicação (CHU, 2003). Este método pode ser aplicado, tanto ex situ (fora do local) quanto in situ (no local), utilizando soluções aquosas de detergentes, para desorver e remover os contaminantes do solo.

Pouco se sabe da combinação entre processos oxidativos utilizando peróxido de hidrogênio e lavagem de solo utilizando tensoativos. No entanto sabe-se da disponibilização que ocorre, através da lavagem, dos contaminantes para a fase aquosa, e também do potencial de oxidação dos aromáticos através da adição de peróxido de hidrogênio, além da dificuldade de se trabalhar com solos argilosos, uma vez que os poluentes tendem a se adsorverem mais facilmente.

Portanto este trabalho teve como objetivo avaliar a eficiência da combinação do processo de lavagem do solo com tensoativos e oxidação química in situ na remediação de solo argiloso contaminado com petróleo.

\section{Experimental}

\section{Local de amostragem e processo de remediação}

Na Refinaria Presidente Getúlio Vargas, situada no município de Araucária, PR, ao sul da região metropolitana de Curitiba, no Primeiro Planalto Paranaense, ocorreu um acidente em julho de 2000, que acarretou no derramamento de 4 milhões de litros de petróleo do tipo Cusiana. As características do petróleo derramado são $0,025 \%$ de água e sedimentos; densidade de 0,$9817 ; 0,21 \%$ de enxofre total e $2,316 \mathrm{~mm}^{2} \mathrm{~s}^{-1}$ para viscosidade cinemática a $40{ }^{\circ} \mathrm{C}$. Quanto à concentração de hidrocarbonetos, é classificado como óleo do tipo parafínico na faixa de $\mathrm{C}_{10}$ e $\mathrm{C}_{14}$ com $71 \%$ de compostos saturados, $18 \%$ de compostos aromáticos, $10 \%$ de resinas e $1 \%$ de asfaltenos (RODRIGUES et al., 2006).

Uma área de $126 \mathrm{~m}^{2}$ (253'05"S 49²1'20”W) foi selecionada para aplicação de tecnologia de remediação utilizando os surfactantes Dodecil ou Lauril sulfato de sódio (SDS) produzido pela All Chemistry do Brasil LTDA e o Dodecil ou Lauril éter sulfato de sódio (LESS) da Agequímica - Comércio de Produtos Químicos LTDA. Como agente oxidante foi utilizado o peróxido de hidrogênio (50\%) Hyprox 500 - Evonik Industries. A área foi dividida em quatro células (A, B, C e D) correspondendo a aproximadamente $4,05 \mathrm{~m}^{3}$ de solo com área superficial de $13,5 \mathrm{~m}^{2}$. Tomando a densidade do solo igual a $1,25 \mathrm{~g} / \mathrm{mL}$, estimou-se cerca de $5000 \mathrm{~kg}$ de solo por célula.

\section{Amostragem do perfil de solo contaminado}

A amostragem do perfil de solo em cada célula (A, B, C e D) foi realizada utilizando amostrador Geoprobe com liner de PVC. Foram obtidas amostras em triplicata, de cada célula A, B, C e D, até $30 \mathrm{~cm}$ de profundidade. Em seguida, os liners preenchidos com solo foram vedados com suas respectivas tampas, etiquetados e acondicionados para transporte até o laboratório. 
Uma primeira amostragem do solo contaminado foi feita em dezembro de 2006 antes de iniciado o período de remediação. O solo tratado in situ foi coletado antes e durante as etapas do tratamento, que ocorreram em dezembro de 2006; janeiro, março, maio, agosto e novembro de 2007.

Foi também coletado solo não-contaminado (referência) a $20 \mathrm{~m}$ de distância da área sob remediação.

Lavagem do solo e aplicação de peróxido de hidrogênio

$\mathrm{Na}$ lavagem do solo com tensoativos e aplicação de peróxido de hidrogênio foi utilizado um Pulverizador Costal Manual da marca Jacto-Supremo, constituído por um tanque em polietileno de alta densidade com capacidade para $16 \mathrm{~L}$, acoplado a uma bomba de diafragma com acionamento manual através de alavanca.

$\mathrm{Na}$ célula $\mathrm{A}$, não foi adicionado qualquer produto, sendo esta mantida como célula controle durante todo o período de tratamento. $\mathrm{Na}$ célula $\mathrm{B}$, foi adicionado $20 \mathrm{~L}$ de água; na célula $\mathrm{C}, 20$ L de solução aquosa de LESS na concentração de $25 \mathrm{~g} / \mathrm{L}$; e na célula $\mathrm{D}$, foi adicionada uma solução aquosa de 20 L de SDS também numa concentração de $25 \mathrm{~g} / \mathrm{L}$ (três vezes acima da CMC). As soluções continham $500 \mathrm{~g}$ de cada surfactante para serem aplicadas no solo das células $\mathrm{C}$ e $\mathrm{D}$, na razão de $0,1 \mathrm{~g} / \mathrm{kg}$ ou $0,01 \%$. Antes e após $20 \mathrm{~h}$ de aplicação das soluções foram realizadas amostragens do solo. Prosseguindo o tratamento, foram aplicados no solo da célula $\mathrm{B}, \mathrm{C}$ e D, $10 \mathrm{~L}$ de solução aquosa contendo $1 \% \mathrm{v} / \mathrm{v}$ de peróxido de hidrogênio 50 $\%$, na razão $0,2 \mathrm{~mL} / \mathrm{kg}$ ou $0,02 \%$. Após $4 \mathrm{~h}$ de aplicação do agente oxidante foi realizada outra amostragem de solo, totalizando três amostragens em cada etapa do tratamento.

\section{Preparação e secagem do solo coletado}

No laboratório, o perfil de solo coletado nas células A, B, C e D foi retirado do liner e separado em camadas de $10 \mathrm{~cm}$, representando amostras de solo superficial (0-10 $\mathrm{cm}$ de profundidade) e solo subsuperficial (10-20 e 20-30 $\mathrm{cm}$ de profundidade).

De cada amostra foi retirada $2 \mathrm{~g}$ de solo úmido e depositado em papel filtro, o qual foi inserido em funil de Buchner devidamente conectado a um sistema de vácuo produzido por uma bomba mecânica NASH do Brasil Bombas Ltda MHC 80/5 com pressão de $300 \mathrm{~mm} \mathrm{Hg}$. A cada intervalo de $15 \mathrm{~min}$. as amostras foram retiradas do sistema para pesagem, sendo este procedimento realizado até peso constante.

\section{Processo de extração do contaminante no solo}

Em porções contendo $1 \mathrm{~g}$ de solo seco foi adicionado $100 \mathrm{~mL}$ de diclorometano Nuclear grau PA. A suspensão foi levada para agitação mecânica em mesa Tecnal TE-140, permanecendo por 1 hora a $200 \mathrm{rpm}$. O extrato foi filtrado em papel filtro.

\section{Análise do extrato de solo por fluorescência}

Os espectros de fluorescência dos extratos orgânicos do solo foram obtidos utilizando-se equipamento Shimadzu RF5301PC, na modalidade synchronous com $\Delta \lambda=20 \mathrm{~nm}$, varredura rápida entre 250 e $800 \mathrm{~nm}$ e band pass de 1,5 nm. Foram calculadas as áreas integradas dos espectros utilizando o software Personal Fluorescence RF5301-PC versão 1.40, tomando-se o intervalo de 300 a $600 \mathrm{~nm}$.

Determinação de BTEX e HPA no solo por CG-DIC

A análise de HPAs foi realizada a partir dos extratos de solo, concentrados em tubo aquecedor/minicondensador (UNITED STATES 
ENVIRONMENTAL PROTECTION AGENCY - USEPA, 2007c) através de CG-DIC (USEPA, 2005), assim como, a análise de BTEX no solo pelo método de extração headspace (USEPA, 2007a). As metodologias para análise de HPA e BTEX foram otimizadas como descrito em Silva et al. (2006) e Melquiades et al. (2006), respectivamente.

Os limites de quantificação para HPA foram: 0,2 $\mathrm{mg} / \mathrm{kg}$ para naftaleno; $20 \mathrm{mg} / \mathrm{kg}$ para acenafteno, fenantreno, antraceno, pireno, criseno, benzo(a) antraceno, benzo(a)fluoranteno, benzo(k) fluoranteno, benzo(a)pireno e indeno(1,2,2cd) pireno; $40 \mathrm{mg} / \mathrm{kg}$ para acenaftileno, fluoranteno, benzo(ghi)perileno e dibenzo(a,h)antraceno. Em se tratando de BTEX, o limite de quantificação foi de $0,05 \mathrm{mg} / \mathrm{kg}$ de solo.

As análises cromatográficas foram realizadas em equipamento Shimadzu GC-17A. As condições cromatográficas foram: volume de injeção $2 \mu \mathrm{L}$ (modo splitless); coluna DB-1 $100 \%$ siloxano (J\&W Scientific) $30 \mathrm{~m} \times 0,25 \mathrm{~mm} \times 0,25 \mu \mathrm{m}$; temperatura do injetor $=200{ }^{\circ} \mathrm{C}$; temperatura da coluna: $\mathrm{T}_{\mathrm{i}}=100$, $\mathrm{T}_{\mathrm{f}}=300^{\circ} \mathrm{C}$, programação $=5^{\circ} \mathrm{C} /$ minuto, $10 \mathrm{~min}$. na $\mathrm{T}_{\mathrm{f}}$; temperatura do detector $=300{ }^{\circ} \mathrm{C}$; composição da chama: ar sintético/hidrogênio 30/1 e gás de arraste nitrogênio com vazão de $1,5 \mathrm{~mL} / \mathrm{min}$.

Os frascos para coleta de solo, técnicas de preservação e intervalo de tempo entre coleta e análise das amostras, estiveram de acordo com os procedimentos Method SW846 (USEPA, 2007b).

Determinação de parâmetros físicos e químicos do solo

O teor de matéria orgânica no solo contaminado (Célula A) e no solo não-contaminado (solo de referência) foi determinado, utilizando-se o método de titulação após oxidação por via úmida (PAVAN et al., 1992), conhecido como método Walkley-Black.

O teor de umidade e as medidas de $\mathrm{pH}$ foram determinados no solo de referência e no solo contaminado das células A, B, C e D. Para determinação de umidade, o solo foi pesado, colocado em estufa a $105^{\circ} \mathrm{C}$ durante $24 \mathrm{~h}$. As amostras foram transferidas para dessecador e novamente pesadas até massa constante. Através da diferença de massa foi determinado o teor de umidade (EMPRESA BRASILEIRA DE PESQUISA AGROPECUÁRIA, 1997). A medida de $\mathrm{pH}$ do solo foi realizada pelo método do $\mathrm{CaCl}_{2}$ (PAVAN et al., 1992) com determinação em pHmetro OAKTON pH 5 Accorn.

A análise granulométrica do solo contaminado foi realizada pelo Método da Pipeta com agitação lenta, de acordo com as orientações da Embrapa (1997).

\section{Amostragem de água na franja capilar}

Foram coletadas amostras de água na franja capilar, zona não-saturada do solo, por toda a extensão da área de remediação, a montante e a jusante da área de remediação em um trecho de canal fluvial não-permanente (Arroio Saldanha) situado em paralelo a área sob tratamento, através de perfuração feita no solo com trado manual até $40 \mathrm{~cm}$ de profundidade. A amostragem de água foi realizada com um amostrador do tipo Bailer introduzido de 30 a $40 \mathrm{~cm}$ da superfície, sem tocar as paredes internas da seção vertical do solo.

\section{Análise físico-química de água na franja capilar}

As medidas de $\mathrm{pH}$, temperatura e oxigênio dissolvido (OD) na água da franja capilar e no Arroio Saldanha foram determinadas in situ utilizando uma sonda multiparâmetros Horiba W-23XD introduzida na seção vertical do solo, a partir da superfície até $30-40 \mathrm{~cm}$ de profundidade.

\section{Determinação de fenóis totais e tensoativos}

A água coletada na franja capilar do solo e no Arroio Saldanha, a montante e a jusante da área de remediação foram analisadas pelo método colorimétrico utilizando 4-aminoantipirina para 
determinação de fenóis totais (AMERICAN WATER WORKS ASSOCIATION, 1995b) em equipamento FEMTO 482 com leitura de absorvância no visível a $460 \mathrm{~nm}$. Foi preparada uma curva de calibração utilizando soluções padrões de fenol nas concentrações 0,$04 ; 0,11 ; 0,18 ; 0,36$; 0,$54 ; 0,72 ; 0,90$ e $1,08 \mathrm{mg} / \mathrm{L}$. O limite de detecção do método é $0,005 \mathrm{mg} / \mathrm{L}$.

O ensaio para determinação de substâncias tensoativas foi realizado com amostras de água coletada na franja capilar e no Arroio Saldanha, a montante e a jusante da área de remediação através do método colorimétrico utilizando azul de metileno (AMERICAN WATER WORKS ASSOCIATION, 1995a) em equipamento FEMTO 482 com leitura de absorvância no visível a $652 \mathrm{~nm}$. Foi preparada uma curva de calibração utilizando soluções padrões de SDS nas concentrações 0,$01 ; 0,05 ; 0,1 ; 0,15$ e 0,20 $\mathrm{mg} / \mathrm{L}$. O limite de detecção para este método é 0,01 $\mathrm{mg} / \mathrm{L}$.

\section{Análise da água por fluorescência}

Espectros de fluorescência das amostras de água coletada na da franja capilar do solo sob remediação e no Arroio Saldanha, a montante e a jusante da área de remediação foram obtidos em espectrofluorímetro (Shimadzu RF-5301PC) na modalidade synchronous com $\Delta \lambda=20 \mathrm{~nm}$, velocidade rápida de varredura entre 250 e $750 \mathrm{~nm}$ e band pass de 1,5 $\mathrm{nm}$.

\section{Resultados}

As características físicas e químicas do solo e concentrações de contaminantes podem influenciar significativamente no comportamento de xenobióticos na matriz ambiental. Por exemplo, um solo próximo da superfície que tenha uma quantidade baixa de umidade e um conteúdo elevado de material orgânico, tende a reter contaminantes de elevada massa molecular.
Os teores de umidade determinados nas amostras coletadas (dezembro de 2006 e novembro de 2007) no solo não-contaminado e contaminado encontram-se na tabela 1. A porcentagem de umidade no solo contaminado foi o dobro daquela verificada no solo de referência, pois a região mais baixa, onde o petróleo ficou retido, trata-se de uma área de Banhado, enquanto que o solo de referência foi coletado em uma área mais elevada, onde o solo não foi contaminado.

Os valores de $\mathrm{pH}$ indicativos de acidez no solo (Tabela 2) são típicos do solo da região, formado por associações entre gleissolos e cambissolos, na sua maioria com textura argilosa e relevo plano, com diversas características relacionadas ao hidromorfismo (SIQUEIRA et al., 2001). O solo contaminado apresentou-se ligeiramente mais ácido, com valor médio de $\mathrm{pH}=3,96$ e o solo de referência com valor médio de $\mathrm{pH}=4,22$. Isto se deve à degradação oxidativa de constituintes do petróleo, dando origem a fenóis e ácidos carboxílicos, que liberando $\mathrm{H}^{+}$contribuem para elevar os índices de acidez no solo (MORRISON; BOYD, 2005).

A porcentagem de matéria orgânica no solo contaminado foi maior do que aquela determinada no solo de referência, devido principalmente a presença do poluente, além de substâncias húmicas e restos de vegetação, pois se trata de solo alagado, naturalmente rico em matéria orgânica (Tabela 3).

A análise textural ou distribuição granulométrica (Tabela 4) confirmou que o solo da região atingida pelo derramamento de petróleo é tipicamente argiloso, funcionando como uma barreira horizontal impermeável, impedindo ou dificultando a contaminação das águas subterrâneas. A porcentagem de areia aumenta com a profundidade e a porcentagem de silte + argila diminui.

Tabela 1 - Porcentagens de umidade no solo

\begin{tabular}{ccc}
\hline & Solo não-contaminado & Solo contaminado \\
\hline Dez/06 & $20,33 \pm 0,51$ & $41,8 \pm 0,80$ \\
Nov/07 & $21,66 \pm 0,57$ & $40,33 \pm 0,57$ \\
\hline
\end{tabular}


Tabela 2 - Valores de pH no solo.

\begin{tabular}{ccc}
\hline Solo contaminado & $(\mathrm{dez} / 06)$ & $($ nov/07) \\
\hline Célula A & $3,95 \pm 0,02$ & $4,04 \pm 0,05$ \\
Célula B & $3,94 \pm 0,06$ & $3,94 \pm 0,02$ \\
Célula C & $3,96 \pm 0,05$ & $3,83 \pm 0,05$ \\
Célula D & $4,01 \pm 0,01$ & $3,98 \pm 0,01$ \\
\hline Solo não-contaminado & $4,22 \pm 0,02$ & $4,20 \pm 0,01$ \\
\hline
\end{tabular}

Tabela 3 - Porcentagens de carbono orgânico e matéria orgânica no solo.

\begin{tabular}{lll}
\hline & Solo não-contaminado & Solo contaminado \\
\hline Carbono orgânico & $1,89 \pm 0,37$ & $4,4 \pm 0,29$ \\
\hline Matéria orgânica & $3,27 \pm 0,65$ & $7,56 \pm 0,49$
\end{tabular}

Tabela 4 - Distribuição granulométrica no perfil do solo contaminado.

\begin{tabular}{ccccc}
\hline $\begin{array}{c}\text { Profundidade } \\
\text { no solo }\end{array}$ & $\begin{array}{c}\text { Areia } \\
(\%)\end{array}$ & $\begin{array}{c}\text { Silte } \\
(\%)\end{array}$ & $\begin{array}{c}\text { Argila } \\
(\%)\end{array}$ & $\begin{array}{c}\text { Finos (silte + argila) } \\
(\%)\end{array}$ \\
\hline $0-10 \mathrm{~cm}$ & 12 & 27,5 & 60,5 & 88 \\
$10-20 \mathrm{~cm}$ & 16 & 20 & 64 & 84 \\
$20-30 \mathrm{~cm}$ & 17 & 0 & 83 & 83 \\
\hline
\end{tabular}

Grande parte da região atingida pelo derramamento de petróleo é alagada e drenada periodicamente, e com isto, o poluente que está retido abaixo da superfície do solo, como fase residual, pode ser empurrado para a superfície devido à capilaridade da água. Os contaminantes que migram para a superfície do solo se encontram em fase livre, dissolvida ou adsorvida, estando sujeitos a processos de intemperismo.

Com o propósito de verificar a contaminação do solo por aromáticos de petróleo, foram obtidos espectros de fluorescência de extratos do solo contaminado, coletado no perfil de 10 a $20 \mathrm{~cm}$ de profundidade na área contaminada (célula D) em dezembro de 2006, antes de iniciado o processo de remediação. Os picos característicos de constituintes do petróleo na faixa de 300 a $600 \mathrm{~nm}$ (NICODEM et al., 2001) e substâncias húmicas entre 650 e $700 \mathrm{~nm}$, encontram-se indicados na figura 1. Os espectros de fluorescência indicaram a presença de
HPAs, constituintes aromáticos polares e asfaltenos do petróleo retidos no solo.

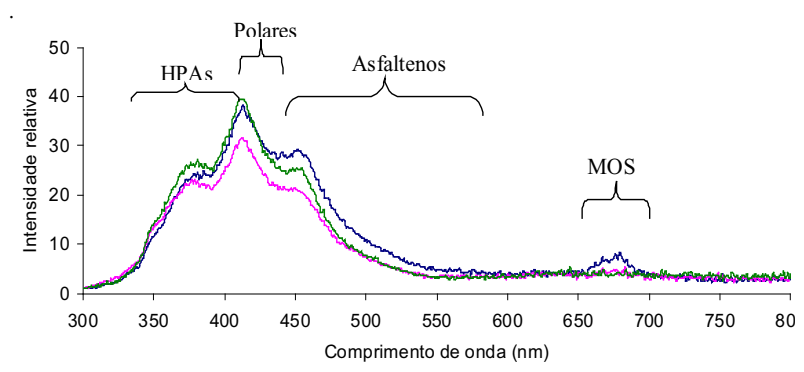

Figura 1. Espectros de fluorescência dos extratos orgânicos de solo coletado em dezembro de 2006.

O processo de lavagem do solo com tensoativos e posterior aplicação de agente oxidante foi utilizado para tratamento da área contaminada com petróleo. A ação de surfactantes no solo ocorre inicialmente por adsorção nas partículas mais finas, argila e silte. A finalidade da lavagem com surfactantes aniônicos é facilitar a transferência de derivados do óleo retidos no solo para o meio aquoso, aumentando as chances de degradação destes contaminantes.

Realizados os procedimentos para remediação da área contaminada e coletadas as amostras para análise por espectroscopia de fluorescência utilizando os extratos orgânicos do solo observou-se que os derivados do petróleo estiveram principalmente concentrados na camada superficial do solo. A percolação destes para as camadas inferiores do solo pode ter sido impedida ou dificultada pela camada de argila encontrada na sub-superfície do solo.

$\mathrm{Na}$ figura 2, a intensidade relativa de fluorescência correspondente a camada superficial do solo $(0-10 \mathrm{~cm})$ na célula $B$, onde foi realizada a lavagem com água, aumentou 25\% (coluna bege) em relação ao solo não lavado (coluna laranja), ocorrendo mobilização dos constituintes aromáticos de petróleo. E assim, com aplicação do peróxido, notou-se diminuição de $60 \%$ na fluorescência (célula $\mathrm{B}$ - coluna amarela) devido à degradação ou consumo dos derivados do óleo. $\mathrm{Na}$ célula $\mathrm{C}$ onde 
houve lavagem do solo com o tensoativo LESS (coluna verde), observou-se que a fluorescência aumentou em apenas 19\%, demonstrando que este tensoativo foi pouco eficiente na solubilização do óleo, tornando a ação do peróxido ineficiente. $\mathrm{Na}$ célula $\mathrm{D}$, onde ocorreu a lavagem do solo com SDS, a fluorescência aumentou em 242\% (coluna azul), indicando maior disponibilidade dos constituintes do óleo, pois este tensoativo, devido as suas propriedades, tende a se ligar fracamente ao solo, liberando grande parte do óleo para a fase aquosa (MESQUITA, 2004). A ação do peróxido de hidrogênio foi mais eficiente neste caso (célula D, coluna amarela) para a degradação da fração solúvel e fluorescente do óleo, oxidando aproximadamente $78 \%$ dos aromáticos disponibilizados no solo pelo surfactante. A adição de surfactantes reduz o ângulo de contato na interface solo/composto orgânico/ água, e como resultado, o composto orgânico sofre o efeito roll-up, podendo ser facilmente separado da matriz solo. Em pH baixo, quando a superfície do solo está carregada positivamente, a adsorção do tensoativo aniônico aumenta, sendo que a afinidade entre a parte polar do tensoativo e o solo está relacionada à teoria da dupla camada difusa (MITCHEL, 1993). Uma vez solubilizado o contaminante, ou seja, em fase livre, torna-se mais acessível à degradação pelo agente oxidante.

Nesta primeira etapa de tratamento do solo, considerando a camada de 10 a $20 \mathrm{~cm}$ (Figura 3), houve uma pequena disponibilização de aromáticos (23\%) após a lavagem do solo com água na célula $\mathrm{B}$ (coluna bege). No entanto, na célula D (coluna azul) a fluorescência aumentou em $47 \%$ e a ação do peróxido na degradação dos aromáticos, após a lavagem com solução de SDS, foi mais eficiente do que na célula submetida à lavagem apenas com água (célula B) ou com solução do surfactante LESS (célula C).
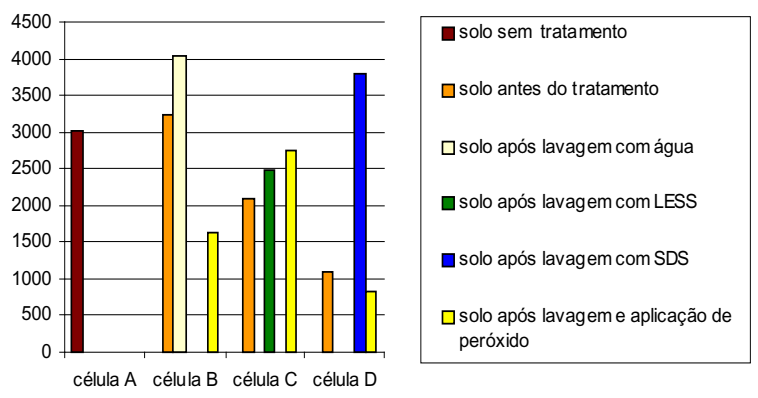

Figura 2. Média das áreas integradas dos espectros de fluorescência (300 a $600 \mathrm{~nm}$ ) nos extratos de solo superficial $(0-10 \mathrm{~cm})$ coletado em dezembro de 2006 durante a primeira etapa de tratamento do solo.

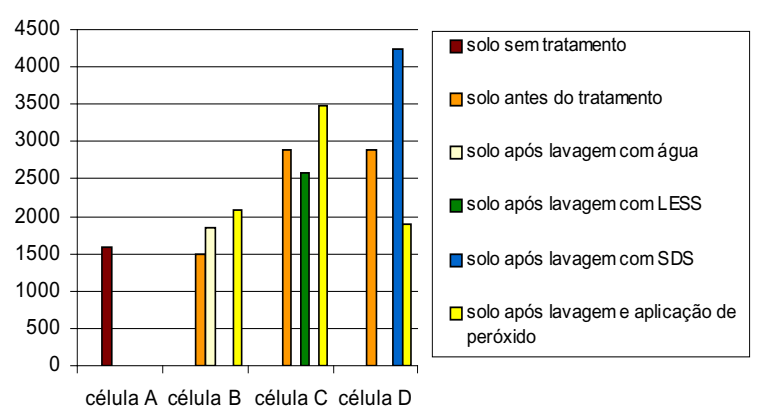

Figura 3. Média das áreas integradas dos espectros de fluorescência (300 a $600 \mathrm{~nm}$ ) nos extratos de solo (10-20 $\mathrm{cm})$ coletado em dezembro de 2006 durante a primeira etapa de tratamento do solo.

Considerando ainda a primeira etapa de tratamento do solo, na camada mais profunda (20 a $30 \mathrm{~cm}$ ), onde havia menor concentração relativa de aromáticos do petróleo residual, provavelmente não ocorreu penetração da solução da solução de lavagem, pois não foi observado aumento de fluorescência relativa à mobilização de aromáticos. A textura argilosa da matriz pode dificultar a penetração dos agentes de remediação.

A eficiência do processo de remediação durante o período de monitoramento foi também avaliado considerando-se o solo sob influência de variações climáticas de acordo com o SIMEPAR - Tecnologias e informações ambientais. Assim, homogeneizando as amostras correspondentes as camadas do solo ( 0 $10 \mathrm{~cm}, 10-20 \mathrm{~cm}$ e $20-30 \mathrm{~cm}$ ) foram obtidas amostras 
representativas do perfil de solo contaminado para análise por fluorescência.

O índice de precipitação na área sob remediação foi de 2,4 mm durante a primeira etapa de remediação (dezembro/2006), contribuindo para a mobilização dos contaminantes e eficiência do processo de remediação, aumentando, por exemplo, em $20 \%$ a intensidade de fluorescência após a lavagem do solo com SDS, célula D, como observado na figura 4 .

Em agosto de 2007, a lavagem do solo com detergentes não mobilizou aromáticos de petróleo no solo (Figura 5). Isso pode ter ocorrido devido ao período de estiagem, quando foi registrado em média apenas $0,3 \mathrm{~mm}$ de precipitação, desfavorecendo a ação do tensoativo na solubilização e mobilização do contaminante. Porém, após aplicação da solução aquosa de LESS e peróxido de hidrogênio houve diminuição de aproximadamente $40 \%$ da fluorescência no solo da célula $\mathrm{C}$, decorrente provavelmente da degradação química e fotoquímica dos contaminantes na superfície do solo.

Um ano após a primeira etapa de tratamento do solo, novembro de 2007, o índice de precipitação (3,9 mm) foi equivalente a média anual. As áreas dos espectros de fluorescência dos extratos de solo (Figura 6) revelaram que, após lavagem do solo com SDS (célula D) houve aumento de 45\% na fluorescência, correspondente aos constituintes aromáticos do petróleo disponibilizados no solo. No entanto, apenas 5\% destes aromáticos sofreram degradação após aplicação do agente oxidante, indicando provavelmente que a concentração do peróxido não tenha sido suficiente para atuar na oxidação dos aromáticos mobilizados no solo.

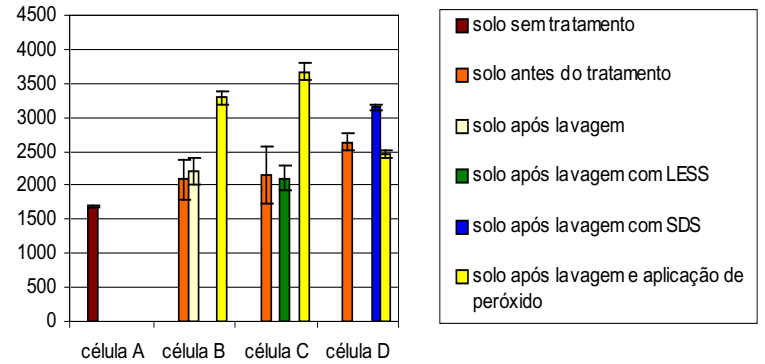

Figura 4. Áreas integradas dos espectros de fluorescência (300 a $600 \mathrm{~nm}$ ) no perfil do solo durante a primeira etapa de remediação (dezembro de 2006).
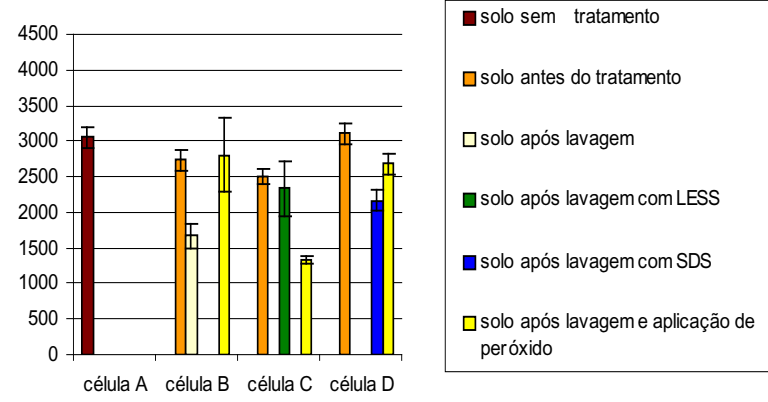

Figura 5. Áreas integradas dos espectros de fluorescência $(300$ a $600 \mathrm{~nm})$ no perfil do solo durante a quinta etapa de remediação (agosto de 2007).

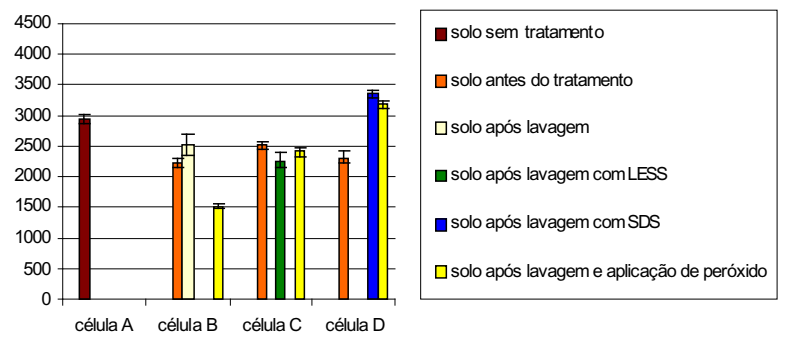

Figura 6. Áreas integradas dos espectros de fluorescência (300 a $600 \mathrm{~nm}$ ) no perfil do solo após um ano (novembro de 2007) com seis etapas de remediação.

A análise por CG-DIC não detectou BTEX no solo contaminado durante todo o período de monitoramento. A análise do solo contaminado buscando identificar e quantificar os 16 HPAs controlados pela USEPA, através de CG-DIC foi 
realizada com amostras coletadas em janeiro, março e novembro de 2007.

O indeno (1,2,3-cd)pireno, com seis anéis aromáticos, foi detectado em todas as células da área sob remediação. De acordo com os valores orientadores para solo e água subterrânea determinados pela Compania de Tecnologia de Saneamento Ambiental (2005), este HPA foi encontrado em concentração acima do limite de intervenção do solo para atividades agrícolas (2 $\mathrm{mg} / \mathrm{kg}$ de solo seco) em janeiro de 2007 na célula B $(4,8409 \mathrm{mg} / \mathrm{kg})$ submetida a lavagem com aplicação de peróxido; e na célula D $(5,2396 \mathrm{mg} /$ $\mathrm{kg}$ ) submetida a lavagem com SDS e aplicação de peróxido. Menores concentrações de indeno(1,2,3cd)pireno foram observadas na célula C $(2,0690$ $\mathrm{mg} / \mathrm{kg}$ ) submetida a lavagem com LESS e aplicação de peróxido, em março de 2007. O indeno(1,2,3-cd) pireno foi novamente detectado na célula $\mathrm{C}(3,1135$ $\mathrm{mg} / \mathrm{kg}$ ) em novembro de 2007, e nesta ocasião foi observada sua maior concentração na célula $B$ $(8,1291 \mathrm{mg} / \mathrm{kg})$, após seis campanhas de lavagem do solo e aplicação de peróxido.

O benzo(ghi)perileno, também com 6 anéis aromáticos em sua estrutura molecular, esteve persistente no ambiente, independentemente do tipo de tratamento dado ao solo contaminado. A concentração deste HPA no solo atingiu o limite de prevenção.

O benzo(a)pireno que possui 5 anéis benzênicos, é o mais tóxico e geralmente o mais persistente no ambiente, atingiu concentração no solo em nível de prevenção $(0,0751 \mathrm{mg} / \mathrm{kg})$ na célula B em novembro de 2007, onde não foram utilizadas substâncias tensoativas na lavagem do solo, as quais parecem contribuir para reduzir o tempo de permanência do contaminante no ambiente.

Considerando as condições e padrões de qualidade da água (BRASIL, 2005) foram monitorados alguns parâmetros na franja capilar do solo na área sob remediação e no Arroio Saldanha. As medidas de $\mathrm{pH}$, temperatura e oxigênio dissolvido (OD) foram feitas in situ e as determinações de fenóis totais, tensoativos e fluorescência de aromáticos foram realizadas em laboratório.

Os valores de $\mathrm{pH}$ aumentando desde fevereiro até novembro de 2007 (4,5 a 5,8), registrados na franja capilar (30-40 cm de profundidade) do solo na área sob remediação podem ser atribuídos à recuperação do ambiente devido às etapas de tratamento do solo que contribuíram ao longo do período para a remoção e degradação de componentes ou derivados do petróleo. Os valores de $\mathrm{pH}$ detectados, neste mesmo período, no Arroio Saldanha a montante (variando entre 6,2 e 6,8 ) e a jusante (variando entre 6,3 e $6,9)$ da área de remediação atendem ao padrão de qualidade para água doce, demonstrando que neste trecho do Arroio Saldanha não houve interferência dos contaminantes ou dos produtos de remediação no $\mathrm{pH}$ natural da água.

Teores baixos de oxigênio dissolvido podem indicar que houve uma intensa atividade bacteriana decompondo matéria orgânica lançada na água. A baixa concentração de OD no Arroio Saldanha a montante da área de remediação deve ser decorrente de contaminação por matéria orgânica, porém não se deve ao aporte de produtos químicos provenientes da remediação do solo. Por outro lado, o aumento significativo de OD no Arroio Saldanha a jusante da área de remediação, de fevereiro a novembro de 2007, pode ser decorrente da aplicação de peróxido de hidrogênio no solo desta região. Este fenômeno mostrou-se acentuado em fevereiro de 2007, quando o índice de precipitação $(7,1 \mathrm{~mm})$ foi o mais elevado durante todo o período de monitoramento. Já o período de estiagem ocorrido no mês de agosto de 2007 (0,3 mm de precipitação) pode ter sido importante para não disponibilizar o peróxido de hidrogênio, fonte de oxigênio, neste trecho do Arroio Saldanha. A solubilidade do oxigênio, a princípio, não foi favorecida pela baixa temperatura detectada na água (entre 12 e $13{ }^{\circ} \mathrm{C}$ ) no mês de agosto de 2007.

Em águas subterrâneas a quantidade de oxigênio dissolvido é geralmente inferior a $4 \mathrm{mg} / \mathrm{L}$ pelo fato 
de estar fora do alcance da atmosfera. $\mathrm{O}$ oxigênio é mais facilmente dissolvido em águas com pouco material em suspensão. Águas amarelas, devido à carga de argila em suspensão possuem menos oxigênio. Este fenômeno pode explicar as baixas concentrações de OD (variando de 2,4 a $3,9 \mathrm{mg} / \mathrm{L}$ ) detectadas na franja capilar do solo a $30-40 \mathrm{~cm}$ de profundidade, que além do elevado teor de argila, conta com o aporte de substâncias orgânicas provenientes da dissolução dos derivados de petróleo.

Os fenóis e seus derivados podem surgir nas águas naturais através das descargas de efluentes industriais ou acidentes com derramamento de alguns produtos químicos orgânicos. Os fenóis são tóxicos ao homem e aos organismos vivos em geral. Efluentes fenólicos ou águas residuárias contendo fenóis devem sofrer tratamento de modo a reduzir o índice de fenóis para abaixo do padrão de emissão no corpo receptor. Quando se trata do lançamento de efluentes, o padrão estabelecido para a concentração de fenóis totais é no máximo 500 $\mu \mathrm{g} / \mathrm{L}$. Neste caso, não foram detectados fenóis totais na franja capilar do solo na área sob remediação ou no Arroio Saldanha a montante e a jusante da área de remediação durante o período de dezembro/2006 a novembro/2007.

Não houve registro da presença de detergente aniônico na franja capilar da área de remediação do solo ou no Arroio Saldanha a montante e a jusante durante o período de dezembro de 2006 a novembro de 2007, indicando que não houve contaminação das águas naturais pelos surfactantes utilizados na remediação do solo.

Não houve registro de fluorescência decorrente dos aromáticos de petróleo na franja capilar do solo sob tratamento ou no Arroio Saldanha a montante ou a jusante da área de remediação durante o período de dezembro/2006 a novembro/2007). Em novembro de 2007, a água coletada na franja capilar do solo sob tratamento apresentou fluorescência correspondente a substâncias húmicas componentes da matéria orgânica natural do solo.
A principal característica das substâncias húmicas $(\mathrm{SH})$ é o componente estrutural básico, o anel benzênico. As SH apresentam-se como misturas heterogêneas de moléculas polidispersas com elevada massa molar. Possuem alto teor de grupos funcionais com oxigênio, na forma de carboxila, hidroxila fenólica e carbonila. As $\mathrm{SH}$ aquáticas compreendem cerca de um terço até a metade do carbono orgânico dissolvido na água e podem apresentar concentração de $20 \mathrm{mg}$ $\mathrm{L}^{-1}$ em águas subsuperficiais (ROCHA; ROSA; CARDOSO, 2004).

\section{Conclusão}

O solo atingido pelo vazamento de petróleo ocorrido na Refinaria Presidente Getúlio Vargas, Araucária, PR em julho de 2000, quando avaliado durante o ano de 2007, apresentou em média $41 \%$ de umidade, enquanto no solo não-contaminado este parâmetro ficou em torno de 21 \%. As medidas de $\mathrm{pH}$ indicaram que o solo contaminado apresenta-se ligeiramente mais ácido $(\mathrm{pH}=3,9)$ do que o solo de referência $(\mathrm{pH}=4,2)$. A MO no solo de referência foi $3,27 \%$ e no solo contaminado foi pelo menos duas vezes maior $(7,56 \%)$. A análise granulométrica confirmou que o solo contaminado é argiloso com $85 \%$ em média de finos (silte + argila), o que deve ter dificultado a penetração do contaminante devido à textura impermeável, e ainda, pode contribuir para a permanência do poluente orgânico no solo devido a sua interação com minerais da argila.

A análise por espectroscopia de fluorescência indicou através da intensidade relativa, maior concentração relativa dos constituintes aromáticos do petróleo na camada superficial do solo, principalmente até $20 \mathrm{~cm}$ de profundidade. A lavagem do solo com água ou solução de surfactante, Lauril (ou dodecil) éter sulfato de sódio (LESS) foi menos eficiente na mobilização e disponibilização dos constituintes aromáticos do petróleo no solo. A lavagem do solo com o surfactante, Lauril (ou dodecil) sulfato de sódio (SDS) foi mais eficiente 
na solubilização da fração aromática do petróleo. A mobilização de aromáticos no solo esteve relacionada à quantidade de chuvas ocorridas na região, e assim, a atuação do peróxido de hidrogênio aplicado in situ após o processo de lavagem esteve vinculada à disponibilidade do aromático de petróleo no solo, altos índices de precipitação tiveram influencia positiva na remediação do solo.

Dentre os 16 HPAs investigados durante a remediação do solo foram detectados: acenafteno, fluoranteno, benzo(a)antraceno, criseno, benzo(b) fluoranteno, benzo(k)fluoranteno, benzo(a)pireno, benzo(ghi)perileno e indeno(1,2,2-cd)pireno. O indeno(1,2,3-cd)pireno foi detectado em todas as células da área sob remediação, em concentração acima do limite de intervenção do solo para atividades agrícolas. O benzo(ghi)perileno, esteve persistente no ambiente, independentemente do tipo de tratamento dado ao solo contaminado, e sua concentração no solo atingiu apenas o limite de prevenção. O benzo(a)pireno também esteve presente no solo em nível de prevenção apenas no local onde não foram utilizadas substâncias tensoativas na lavagem do solo. Na ocasião que ocorreu maior mobilização e/ou disponibilização de HPA no solo foi em fevereiro de 2007, ocasião em que o índice de precipitação foi de $7,1 \mathrm{~mm}$, ou seja, o maior índice observado durante o ano. Quanto menor a massa molecular do contaminante e maior a quantidade de chuvas na região, tanto maior é a mobilidade do HPA no solo.

Os valores de $\mathrm{pH}$ monitorados na solução do solo sob remediação, desde fevereiro até novembro de 2007 ( $\mathrm{pH} 4,5$ a 5,8), foram indicativos da recuperação do ambiente, provavelmente decorrente da remediação do solo contaminado. Os valores de $\mathrm{pH}$ detectados, neste mesmo período, no Arroio Saldanha a montante (pH 6,2 a 6,8) e a jusante $(\mathrm{pH}$ $6,3$ a 6,9$)$ da área de remediação atendem ao padrão de qualidade para água doce.

A concentração de OD no Arroio Saldanha, a jusante da área de remediação, pode ser decorrente da remediação do solo, especialmente da aplicação de peróxido de hidrogênio, e do elevado índice de precipitação $(7,1 \mathrm{~mm})$ na região.

A concentração de fenóis totais e substâncias tensoativas estiveram abaixo do limite máximo estabelecido para qualidade da água, tanto na solução do solo quanto no Arroio Saldanha. Também, não houve registro de fluorescência na água coletada na franja capilar do solo na área sob remediação ou no Arroio Saldanha durante o período de monitoramento, sendo que a fluorescência detectada corresponde à matéria orgânica natural do solo.

A combinação dessas duas técnicas, lavagem do solo e aplicação de agente oxidante, pode ser um processo de remediação eficaz para solos contaminados com derivados de petróleo, no entanto maiores concentrações do peróxido de hidrogênio devem ser utilizadas para aumentar a eficiência desta tecnologia.

\section{Referências}

AMERICAN WATER WORKS ASSOCIATION AWWA. Method 5540C. Anionic Surfactants as MBAS: standard methods for the examination of water and wastewater. $19^{\text {th }}$ ed. Washington: AWWA, 1995a.

. Method 5530C. Chloroform Extraction Method: standard methods for the examination of water and wastewater. $10^{\text {th }}$ ed. Washington: AWWA, 1995b.

BARATHI, S.; VASUDEVAN, N. Utilisation of petroleum hydrocarbons by pseudomonas fluorescens isolated from a petroleum-contaminated soil. Environmental International, New York, v. 26, n. 5/6, p. 413-416, 2001.

BHANDARI, A.; NOVAK, J. T.; DOVE, D. C. Effect of soil washing on petroleum hydrocarbon distribution on sand surfaces. Journal Health Services Research, New York, v. 2, p. 1-13, 2000.

BRASIL. Ministério do Meio Ambiente. Conselho Nacional Do Meio Ambiente - Conama. Resolução Conama $n^{\circ} 357$, de 17 de março de 2005. Dispõe sobre a classificação dos corpos de água e diretrizes ambientais para o seu enquadramento, bem como estabelece as condições e padrões de lançamentos de efluentes, e dá outras providências. Brasília, DF, 17 mar. 2005.

CHU, W. Remediation of contaminated soils by surfactant-aided soil washing. Practice Periodical of Hazardous, Toxic, and Radioactive Waste Management, New York, v. 7, n. 1, p. 19-24, 2003. 
CHU, W.; CHAN, K. H. The mechanism of the surfactantaided soil washing system for hydrophobic organics. Science of the Total Environment, Amsterdam, v. 307, n. 1/3, p. 83-92, 2003.

COMPANIA DE TECNOLOGIA DE SANEAMENTO AMBIENTAL - CETESB. Decisão de diretoria $n^{\circ}$. 195-2005-E, de 23 de novembro de 2005. Dispõe sobre a aprovação dos Valores Orientados para Solos e Águas Subterrâneas mo Estado de São Paulo - 2005, em substituição aos Valores Orientados de 2001, e dá outras providências. São Paulo, SP, 23 nov. 2005

EMPRESA BRASILEIRA DE PESQUISA AGROPECUÁRIA - EMBRAPA. Centro Nacional de Pesquisa de Solo. Manual de métodos de análise de solo. 2. ed. Rio de Janeiro:EMBRAPA/CNPS, 1997.

McCRAY, J. E.; BAI, G.; MAIER, J. M.; BRUSSEAU, M. I. Biosurfactant-enhanced solubilisation of NAPL mixtures. Journal of Contaminat Hydrology, Amsterdam, v. 48, n. $1 / 2$, p. $45-68,2001$.

MELQUIADES, R. A.; LOBO, I.; GUEDES, C. L. B.; PINTO, J. P. Análise de benzeno, tolueno, etilbenzeno e xilenos em solos por headspace e cromatografia gasosa/ detector de ionização de chama. Semina: Ciências Exatas e da Tecnológicas, Londrina, v. 27, n. 2, p. 113-120, 2006.

MESQUITA, A. C. Uso das técnicas de oxidação química e biodegradação na remoção de alguns compostos orgânicos recalcitrantes. 2004. Tese (Doutorado em Engenharia Civil) - Universidade Federal do Rio de Janeiro, Rio de Janeiro.

MITCHEL, J. K. Fundamentals of soil behavior. $2^{\text {th }}$ ed. New Jersey: John Wiley and Sons, 1993.

MORRISON, R. T.; BOYD, R. N. Química orgânica. 14. ed. Lisboa: Fundação Calouste Gulbenkian, 2005.

NICODEM, D. E.; GUEDES, C. L. B.; FERNANDES, M. C. Z.; SEVERINO, D.; CORREA, R. J.; COUTINHO, M. C.; SILVA, J. Photochemistry of petroleum. Progress in Reaction Kinetics and Mechanism, Northwood, v. 26, p. 219-238, 2001.

PARIA, S. Surfactant-enhanced remediation of organic contaminated soil and water. Advances in Colloid and Interface Science, Amsterdam, v. 138, n. 1, p. 24-58, 2008

PAVAN, M. A.; BLOCH, M. F.; ZEMPULSKI, H. C.; MIYAZAWA, M.; ZOCOLER, D. C. Manual de análise química de solo e controle de qualidade. Londrina: IAPAR, 1992.

ROCHA, J., C.; ROSA, A. H.; CARDOSO, A. A. Introdução à química ambiental. Porto Alegre: Bookman, 2004.
RODRIGUES, T. T.; WISNEWSKI, C.; BONA, C.; DEDECEK, R. A.; SANTOS, G. O. Caracterização nutricional de branquilho (Sebastiania commersoniana (Baillon) Smith \& Downs - Euphorbiaceae), cultivado em solo contaminado por petróleo. Revista Floresta, Curitiba, v. 36, p. 349-359, 2006.

RIZZO, A. C. L.; LEITE, S. G. F.; SORIANO, A. U.; SANTOS, R. L. C.; SOBRAL, L. G. S. Biorremediação de solos contaminados por petróleo: ênfase no uso de biorreatores. Rio de Janeiro: CETEM, 2006. (Série Tecnologia Ambiental, n. 37).

SILVA, A. A. R.; LOBO, I.; GUEDES, C. L. B.; PINTO, J. P. Análise de hidrocarbonetos policílicos aromáticos (HPAs) em solos utilizando agitação ultra-sônica, tubo aquecedor/minicondensador e cromatografia gasosa. Semina: Ciências Exatas e Tecnológicas, Londrina, v. 27, n. 2, p. 105-112, 2006.

SIQUEIRA, J. D. P.; RODERJAN, C. V.; KIRCHNER, F. F.; SOUSA, L. C. P. Diagnóstico e monitoramento da cobertura vegetal da área de influência direta e indireta do vazamento de óleo de refinaria Presidente Getúlio Vargas - Repar, Araucária/PR, Fase 1 - Diagnóstico. Curitiba: FUNPAR, 2001.

TEIXEIRA, C. P. A. B.; JARDIM, W. F. Processos oxidativos avançados: conceitos teóricos. Campinas: Unicamp, 2004. (Caderno Temático, v. 3).

UNITED STATES ENVIRONMENTAL PROTECTION AGENCY - USEPA. Method 3810: Headspace. Disponível em: $<$ http://www.epa.gov/sw-846/pdfs/3810. pdf $>$. Acesso em: 12 jun. 2007a.

Method 8100: Polynuclear aromatic hydrocarbons. Disponível em: <http://www.epa.gov/ epaoswer/hazwaste/test/pdfs/8100.pdf>. Acesso em: 15 jun. 2005.

. Method 3510C: Separatory funnel liquid-liquid extraction Disponível em: < http://www.epa.gov/SW846/pdfs/3510c.pdf >. Acesso em: nov. 2007b.

Method 3550B: Ultrasonic Extraction. Disponível em: <www.epa.gov/sw-846/pdfs/3550b. pdf $>$. Acesso em: 12 jun. 2007c.

ZHOU, Q.; SUN, F.; LIU, R. Joint chemical flushing of soils contaminated with petroleum hydrocarbons. Environment International, New York, v. 31, n. 6, p. 835-839, 2005.

Recebido em 28 Setembro, 2009 - Received on September 28, 2009. Aceito em 2 julho, 2010 - Accepted on July 2, 2010. 
